\title{
PISCO
}

\section{ADVANCES MADE THROUGH THE FORMATION OF A LARGE-SCALE, LONG-TERM CONSORTIUM FOR INTEGRATED UNDERSTANDING OF COASTAL ECOSYSTEM DYNAMICS}

By Bruce A. Menge, Kristen Milligan, Jennifer E. Caselle, John A. Barth, Carol A. Blanchette, Mark H. Carr, Francis Chan, Robert K. Cowen, Mark Denny, Steven D. Gaines, Gretchen E. Hofmann, Kristy J. Kroeker, Jane Lubchenco, Margaret A. McManus, Mark Novak, Stephen R. Palumbi, Peter T. Raimondi, George N. Somero, Robert R. Warner, Libe Washburn, and J. Wilson White

PISCO Scientist Jonathan Robinson installs larval settlement plates during a low tide along the Oregon coast. Photo credit: Heather Fulton-Bennett

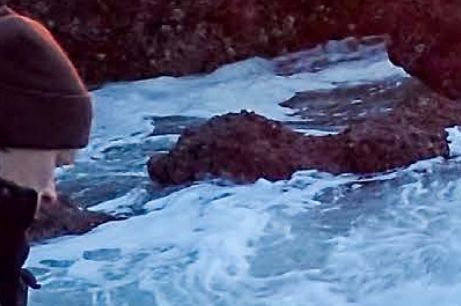


ABSTRACT. To support conservation practices, societal demand for understanding fundamental coastal ocean ecosystem mechanisms has grown in recent decades. Globally, these regions are among the world's most productive, but they are highly vulnerable to extractive and non-extractive stresses. In 1999, we established the Partnership for Interdisciplinary Studies of Coastal Oceans (PISCO) to perform basic and use-inspired, long-term ecological research at local to large marine ecosystem (LME) scales. Coordinated investigations of ecosystem patterns and dynamics focused on nearshore coastal waters and hard-bottom habitats (rocky intertidal and kelp forests) in the California Current Large Marine Ecosystem. Communicating relevant scientific discoveries to inform decision-making was an integral component, as was commitment to training new generations of interdisciplinary marine scientists, thereby building scientific capacity and expertise in marine conservation science and policy. Issues of climate change and ocean acidification, wildlife disease outbreaks, oil spills, and conservation strategies such as marine protected areas have spotlighted the immense value of long-term monitoring and research at the LME scale. Here, we reflect on PISCO's approach and progress in linking science, conservation, management, and policy using 20 years of experience in the formation and operation of this research network.

\section{INTRODUCTION}

By the 1990s, scientific evidence that human activities were degrading Earth's ecosystems was clear (Vitousek et al., 1997; IPCC, 2001). Yet, the full scope of the scale and pace of impacts to marine environments remained uncertain. Over half of the world's population resided in near-coastal regions, placing increasing stress on coastal habitats (Vitousek et al., 1997). Fisheries were nearing crisis, areas of human-driven hypoxia were increasing (Diaz and Rosenberg 1995), and habitat alteration was growing apace. Consequently, many marine scientists increased research efforts that both informed conservation and provided insight into coastal ecosystem functioning (e.g., Cochrane et al., 2009; Ramesh et al., 2015). In many cases, this shift grew from a shortcoming of prior research: existing community studies were too local, small scale, short term, and uncoordinated to detect and facilitate understanding of biogeographic change. Because detecting climate change and its potential impacts was unlikely without a broad geographic perspective, this was a critical problem (Levin, 1992). Yet, federal agencies tasked with funding the relevant research areas responded slowly to this challenge. As a result, obtaining funding for long-term, collaborative research on fundamental mechanisms driving coastal marine eco- systems was, and still is, difficult. Such funding limitations hinder investigation of these systems in the context of climate change and in informing local as well as geographic-scale conservation.

In 1998, scientists from academic institutions in Oregon and California developed a proposal that was funded by the David and Lucile Packard Foundation (DLPF) to create a research consortium aimed at advancing marine coastal science and conservation in the California Current Large Marine Ecosystem (CCLME). The concept was for interdisciplinary marine science research teams to conduct integrated, coordinated studies across a wide biogeographic scale. The initial principal investigator team included population and community ecologists, larval biologists, physiologists, molecular ecologists, and functional biologists; later, experts were added in coastal physical oceanography, biogeochemistry, fishery biology, theoretical ecology, and genomics (Table 1).

\section{SCIENTIFIC MOTIVATION}

\section{Cracking Open the "Black Box"}

of Nearshore Dynamics

Historically, the disparate development of the marine ecological and the oceanographic fields impeded large-scale understanding of coastal ecosystem functioning (Menge, 1992). Though both groups were "ocean" scientists, the methods, questions, approaches, and even the terminology used by the two groups were different. Coastal marine ecologists worked in places accessible by vehicle and foot, or via small vessels (i.e., intertidal or shallow subtidal habitats). These scientists worked at low tides or used scuba to gain access to organisms and habitats of interest. In contrast, oceanographers worked from large ships, were unconstrained by tides, and conducted their studies using a mix of remote sensing, ship-based sampling, and instrumented moorings. Because many oceanographic ships could not work close to shore, the inner shelf (i.e., surf zone seaward to $\sim 50 \mathrm{~m}$ depth) remained oceanographically understudied. That is, the inner shelf was a "black box" with respect to understanding interactions among physical, chemical, and biological factors. This was a serious limitation, given the ecological and economic importance of these regions. Most intertidal and kelp bed biota have dispersive propagules, and marine scientists had little to no knowledge of the movement of these reproductive products (Caley et al., 1996). This lack of information hindered both empirical and theoretical efforts to determine the "connectedness" of alongshore habitats.

Knowledge of inner-shelf dynamics was also crucially important for further development and application of a relatively novel coastal conservation approach-establishment of marine protected areas (MPAs; Lubchenco et al., 2003). MPAs are spatial areas where fishing or other forms of take are prohibited or limited. MPA goals include conservation of biodiversity and fishery recovery. Take restrictions (i.e., collection of organisms, fishing) enable persistence of rare species and facilitate recovery and growth to large size of heavily fished species, thereby facilitating reproductive output (Lester et al., 2009).

To raise awareness of the increasing stressors imposed on coastal oceans, the Partnership for Interdisciplinary Studies of Coastal Oceans (PISCO) PIs also 
deemed as essential the direct communication of relevant scientific discoveries and their implications to policymakers and managers. Historically, information transfer to policymakers and managers through scientific publications was slow, and although knowledge transfer using this method remained important, novel approaches were needed to accelerate information exchange in marine conservation biology (Lubchenco et al., 2003; Reid, 2004).

\section{THE PARTNERSHIP FOR INTERDISCIPLINARY STUDIES OF COASTAL OCEANS}

PISCO was established in 1999 with funding from the David and Lucile Packard Foundation. Four universities formed the core: Oregon State University
(OSU), University of California, Santa Cruz (UCSC), Stanford University, and University of California, Santa Barbara (UCSB; Figure 1). PISCO's conceptual focus was ecosystem resilience and resistance to perturbations, both natural and anthropogenic. We proposed that major conservation advancement depended on studying the CCLME at spatially and temporally appropriate scales (small to large, short to long) using interdisciplinary approaches. Three overarching goals were to:

1. Conduct coordinated investigations of ecosystem patterns and dynamics in inner shelf (rocky intertidal and subtidal) habitats in the CCLME

2. Rapidly communicate relevant scientific discoveries advancing marine conservation to policymakers and manag-

TABLE 1. List of PIs, present and past. PISCO has a legacy of scientific leadership in the many disciplines required for a holistic understanding of marine ecosystems. Under their direction, PISCO generates integrative scientific knowledge and transfers scientific knowledge into policy and management.

\begin{tabular}{|c|c|c|}
\hline $\begin{array}{l}\text { Jane Lubchenco, OSU } \\
\text { (Founding Lead Principal) }^{1}\end{array}$ & $\begin{array}{l}\text { Marine community ecology, communication, outreach, } \\
\text { and policy }\end{array}$ & 1999-2009 \\
\hline Bruce A. Menge, $\mathrm{OSU}^{2}$ & Coastal marine ecosystem structure and dynamics & 1999-present \\
\hline Carol A. Blanchette, UCSB & Intertidal community ecology and biomechanics & 2000-present \\
\hline Mark H. Carr, UCSC & Ecology of nearshore fishes and kelp forests & 1999-present \\
\hline Jennifer E. Caselle, UCSB & Kelp forest ecology and conservation & 1999-present \\
\hline Mark Denny, Stanford & Biomechanics & 1999-present \\
\hline Peter T. Raimondi, UCSC & Marine community ecology and biogeography & 1999-present \\
\hline John A. Barth, OSU & $\begin{array}{l}\text { Physical oceanography and interdisciplinary } \\
\text { oceanography }\end{array}$ & 2004-present \\
\hline Francis Chan, OSU & Biogeochemistry, ecosystem ecology, oceanography & 2010-present \\
\hline $\begin{array}{l}\text { Robert K. Cowen, OSU } \\
\text { (formerly U. Miami) }^{3}\end{array}$ & Fish biology and ecology & 2009-2011 \\
\hline Steven D. Gaines, UCSB & Marine ecology, fishery management and biogeography & 1999-2014 \\
\hline Gretchen E. Hofmann, UCSB & Ecophysiology and ecology & 2004-2012 \\
\hline Kristy J. Kroeker, UCSC & Ecophysiology and ecology & 2018-present \\
\hline $\begin{array}{l}\text { Margaret A. McManus, } \\
\text { U. Hawai'i (formerly UCSC) }\end{array}$ & Physical and interdisciplinary oceanography & 2005-2014 \\
\hline Mark Novak, OSU & Marine community ecology, theory & 2018-present \\
\hline Stephen R. Palumbi, Stanford & Genetics, population biology, evolution, systematics & 2005-present \\
\hline George N. Somero, Stanford & Physiology & 1999-2010 \\
\hline Robert R. Warner, UCSB & Behavioral and evolutionary ecology, population biology & 1999-2014 \\
\hline Libe Washburn, UCSB & Physical and interdisciplinary oceanography & 2005-present \\
\hline J. Wilson White, OSU & Quantitative fisheries ecology & 2018-present \\
\hline
\end{tabular}

J. Lubchenco was the Lead Principal Investigator from 1999 until early 2009, when she was confirmed by the Senate to serve as the Undersecretary of Commerce for Oceans and Atmosphere and the Administrator of the National Oceanic and Atmospheric Administration.

2 B.A. Menge has been Lead Principal Investigator since 2009

R.K. Cowen led a PISCO strategic planning initiative from 2009 to 2011

ers with a focus on marine reserves

3. Build scientific capacity in marine conservation science and policy, and develop novel programs for training the next generation of interdisciplinary marine scientists

Here, using 20 years of experience in the formation and operation of this research network, we describe PISCO's progress toward these goals.

\section{CREATION OF THE \\ SCIENTIFIC PROGRAM}

\section{Establishment of PISCO:}

Scaling Up, Expanding, and Forging New Ground (1999-2004)

Our initial task was developing a research platform that would provide novel insights into physical, chemical, and biological processes operating in the CCLME inner shelf for advancement of conservation biology. Programmatic components were:

1. Installing an instrumented mooring network and sampling program for quantifying oceanic conditions in the inner shelf

2. Initiating a field-based, long-term monitoring program for eventual detection of climate change and other anthropogenic and natural impacts on coastal ecosystems

3. Conducting "process" studies for understanding sub-organismal, organismal, population, and community mechanisms producing patterns and driving dynamics

Focal habitats were hard-bottom intertidal and subtidal communities (e.g., Figure 2), selected because of availability of species with favorable organismal traits (e.g., relatively small size, rapid life histories, mostly sessile or sedentary, responsive to measurable environmental factors). Research was facilitated by deep prior understanding of species interactions and inputs of propagules, nutrients, and phytoplanktonic food, and established investigator expertise. Similarly, focal organisms included fishes, invertebrates, and macrophytes (e.g., Figure 2). 
To achieve the biogeographic coverage proposed, we established a coast-wide network of study sites (Figure 1) with observational and experimental components. These included community surveys, quantification of invertebrate and fish recruitment, and growth of key space occupiers, as well as measuring the strength of species interactions. Logistical constraints confined the majority of the subtidal studies to central and southern California. Concurrent with installation of the scientific component, existing graduate programs were expanded and integrated, new interdisciplinary training programs were initiated, and opportunities for informing policy were sought.

PISCO's research program was jumpstarted by community monitoring and recruitment studies predating its formation. Scientists at OSU, UCSC, and UCSB had conducted intertidal ecological community survey and recruitment monitoring programs for several years. Other programs and sampling techniques were developed de novo. For example, to quantify inner shelf physical (current magnitude and direction, temperature, salinity, and pressure) and biological (phytoplankton biomass) dynamics, we initiated a novel mooring network along the central Oregon and central and southern California inner shelves. While subtidal research had a rich and varied history along the coast, we developed a coordinated and consistent protocol for subtidal community surveys. Such protocols have since been widely adopted along the West Coast (for example, by the Oregon Department of Fish and Wildlife, California Department of Fish and Wildlife, and ReefCheck CA). Quantification of fish recruitment, essential for marine reserve design and implementation, was also enabled by newly developed methodologies (Ammann, 2004).

In ecology, understanding community pattern causation requires study of processes such as species interactions, immigration of new individuals, and inter- actions between environmental conditions and organismal performance. PISCO's creation facilitated large-scale understanding of dynamics through expansion of the "comparative-experimental approach" (Menge and Menge, 2013). This method tests how local processes scale up through the use of coordinated, spatially repeated and geographically dispersed experiments informed by simulta- neous quantification of the physical and biological environment.

In the 1990s, many scientists and policymakers realized that existing safeguards (e.g., fishing quotas, fishery closures) were insufficient for protecting biodiversity and ecosystem functioning (Pauly, 1995; Boonstra and Osterblom, 2014). PISCO scientists helped lead increased engagement by marine scien-

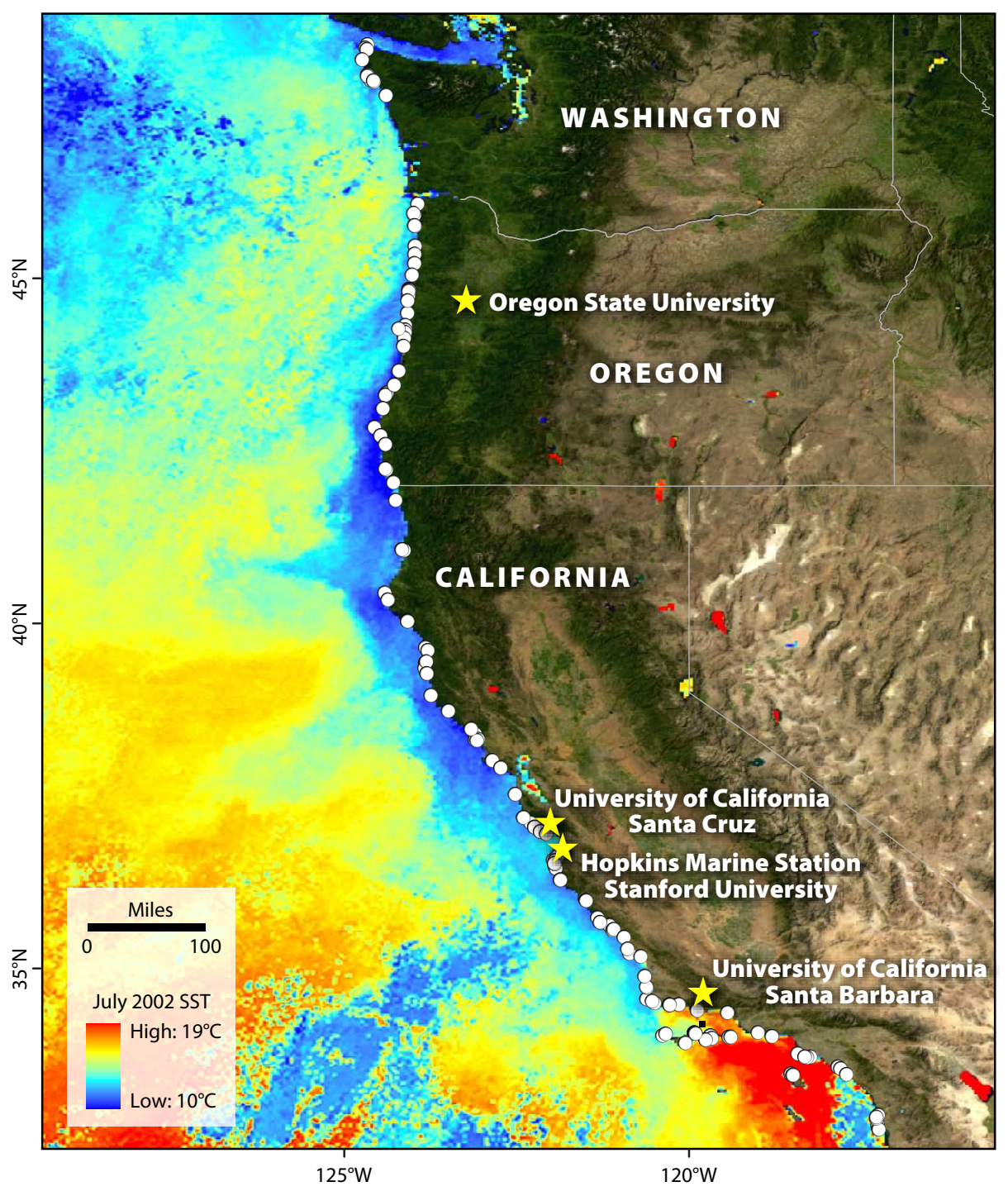

FIGURE 1. Since 1999, the Partnership for Interdisciplinary Studies of Coastal Oceans (PISCO) has studied the California Current Large Marine Ecosystem, which extends more than $3,200 \mathrm{~km}$ (2,000 miles) along the western coasts of the United States and Mexico. The California Current is among the world's most productive and diverse ocean ecosystems. It is one of the four major "eastern boundary current" coastal regions where upwelling brings deep, nutrient-rich water to the surface. The map shows the locations of PISCO campuses, initial distribution of monitoring and research sites, and coastal sea surface temperature (red = warmer; blue = cooler). Dots along the shore identify early sites of monitoring in kelp forest and rocky intertidal habitats. Over time, sites have been added or removed from the long-term monitoring strategy. For example, kelp forest monitoring sites have been added in California as part of the partnerships contributing to monitoring and evaluation of marine protected areas. Graphic by Monica Pessino, Ocean o'Graphics, University of California, Santa Barbara, and Moni Kovacs, Oregon State University 
1999; Feely et al., 2004). However, awareness of the potential ecological impacts of OA lagged. Heightened concerns for the impacts of OA on upwelling ecosystems (Feely et al., 2008) spurred us to augment mooring instrument arrays with newly available $\mathrm{pH}$ and $p \mathrm{CO}_{2}$ sensors to quantify spatiotemporal OA patterns. Our in situ observations provided carbonate chemistry measurements showing that acidified waters bathed the shore and demonstrated that $\mathrm{OA}$ varied non-latitudinally, with "hot" (low, variable $\mathrm{pH}$ ) and "cold" (high, less variable $\mathrm{pH}$ ) spots intermingled along the coast (Chan et al., 2017). Study of biological impacts of OA were initiated by several ecological PISCO PIs and by our new co-PI Gretchen Hofmann, who used molecular, genetic, and physiological approaches to determine how key calcifiers responded to OA conditions (e.g., Hofmann et al., 2010).

These discoveries resulted from our efforts to open the inner shelf "black box.” Our moorings provided a novel inner shelf physical, chemical, and biological time series in a coastal upwelling ecosystem. Specifically, our data revealed broad-scale, upwelling-driven links between deep, low $\mathrm{O}_{2} /$ high $p \mathrm{CO}_{2} /$ nutrient-rich waters; shelf processes such as phytoplankton blooms, hypoxia, and OA; organismal physiological performance; and kelp bed and rocky shore communities. Knowledge of such linkages helped to interpret variation in abundance, growth, physiological condition, and mortality of the biota occurring in these inner shelf habitats.

The successful launch of the Channel Islands marine reserve network in 2003 was followed by the 2007 initiation of a statewide network of marine reserve networks along the entire California coast. Here again, PISCO worked closely with resource managers, agencies, and policymakers in network design and implementation. PISCO scientists helped lead the scientific studies needed for evaluating network effectiveness (Botsford et al., 2014; Carr et al., 2019, in this issue; Lubchenco et al., 2019, in this issue).
Maturation Period: Integration and

Synthesis, Science-to-Policy, and Ecological "Surprises" (2010-2018)

The most recent maturation period began in 2010, with two funding cycles (20102014, 2015-2019). Advances tightened understanding of marine reserve effectiveness, data-poor coastal fishery science, and marine ecosystem dynamics. During this period, DLPF support was reduced but still provided essential core funds that served as leverage in diversifying PISCO funding sources. DLPF and new funding enabled maintenance of long-term monitoring activities, initiation of new process studies, consolidation of our data management network, continued training of students in interdisciplinary approaches to marine conservation science, and further involvement in policy and public outreach. This period was highlighted by integration of research efforts and policy activities on ocean acidification and hypoxia $(\mathrm{OAH})$ through creation of a new, NSF-funded research consortium called OMEGAS (Ocean Margin Ecosystem Group for Acidification Studies). OMEGAS included several current and former PISCO PIs plus additional colleagues from the University of California Davis Bodega Marine Laboratory and the Monterey Bay Aquarium Research Institute. OMEGAS goals included: (1) development of field-deployable $\mathrm{pH}$ sensors and their placement in waveswept intertidal areas and on coastal moorings; (2) testing key species OA tolerances (sea urchins and mussels) in laboratory mesocosms and determining suborganismal OA response mechanisms using molecular, genomic, and transcriptomic tools; (3) examining mussel and sea urchin field responses to OA; and (4) testing OA effects on a key predator-prey interaction (whelks feeding on mussels; Chan et al., 2019, in this issue).

Increased scientific understanding of $\mathrm{OAH}$ dynamics and consequences was accompanied by increased engagement with policymakers and stakeholders by PISCO scientists and their collaborators. These connections helped lawmak- ers and state governors understand links between carbon emissions and coastal $\mathrm{OAH}$ and the value of science in informing proactive state actions. A decade after the emergence of anoxia in the California Current Large Marine Ecosystem, both Oregon and California had enacted legislation directly addressing challenges posed by OAH.

The success of the California MPA network informed policy at national, international, and regional levels, and spurred recognition of the value of scientifically designed MPA networks (Allison et al., 2003; Carr et al., 2019, in this issue; Lubchenco et al., 2019, in this issue). Design and implementation of California's MPAs occurred during 20062012 and progressed region by region across the state. This allowed the science to progress as well, as gradual improvements to the models on such criteria as size and spacing and levels of protection were made over time (Botsford et al., 2014). PISCO scientists participated in all aspects of the process and remain heavily involved in monitoring MPA performance. A further example of PISCO science informing policy has been the participation by PISCO PIs during the establishment and ongoing evaluation of five marine reserves in Oregon (Lubchenco et al., 2019, in this issue).

\section{INTEGRATING OUTREACH, ENGAGEMENT, AND STUDENT TRAINING INTO THE SCIENTIFIC PROGRAM}

\section{Outreach and Engagement}

As noted, because PIs recognized the potential for academia to help meet societal needs for information and knowledge, PISCO committed to communicating its research broadly and training generations of ecosystem science leaders. From the start, we adhered to a nonadvocacy principle; rather, we saw our role as informing management and policy processes and promoting the use of science in conservation efforts.

Through time, we fulfilled our commitment to effective science communica- 
tion in different ways (Lubchenco et al., 2019, this issue). Because we recognized that effective engagement takes time and expertise, policy and outreach coordinators were hired to, for example, help build bridges to management/policy entities and assist in organizing events and presentations and in tailoring research summaries. Important and enduring relationships were developed with COMPASS (http://www.compassscicomm.org) and SeaWeb (https://seaweb.org), two leaders in science communication who provided training for PISCO personnel. Outreach evolved through several forms, initially in print media, such as an annual booklet and the Science of Marine Reserves series, and then with a gradual shift to webbased materials. Downloadable graphics illustrating scientific results and concepts have been in especially high demand (Lubchenco et al., 2019, in this issue).

Since PISCO's establishment, science communication has advanced considerably. The importance of scientists sharing their work beyond academic peers is now widely recognized (Fischoff and Scheufele, 2013; Kahan et al., 2017), and "SciComm" has become a field in itself with dedicated journals and conferences. We continue to serve on advisory panels, give public presentations, form research partnerships on issues of direct societal relevance, and bring science communication and public engagement training into classrooms.

\section{Training}

We aimed to cultivate new generations of marine scientists who would routinely conduct outstanding interdisciplinary research and relate their findings to marine policymakers and management. Across 20 years, nearly 100 graduate students and 50 postdoctoral researchers have completed their studies in one or more PISCO labs. Most have pursued positions in academia, public agencies, and nonprofit organizations. For example, of the $\sim 100$ students completing graduate degrees, 60 obtained positions in higher education, while 40 pursued careers with public agencies, nonprofits, and private industry.

PISCO graduate courses departed from traditional, single-institution approaches. Courses attracted applicants not only from different disciplinary degree tracks within PISCO but also applicants who were students and postdoctoral scholars studying at other institutions. We offered three courses multiple times from 1999 through 2009. An interdisciplinary course entitled "Ecological Physiology and Genetics" was taught by Stanford University PIs at Hopkins Marine Station. The novel course "Science-Policy Interface for Marine Conservation" was taught at Oregon State University and staffed by PISCO PIs from OSU, UCSB, and selected guest lecturers. With increased disciplinary breadth provided by adding PIs with oceanographic expertise, "Physical Oceanography and Marine Ecosystems" was jointly taught by PISCO PIs from OSU, UCSC, and UCSB. Beyond specific learning outcomes from these courses, PIs were committed to providing opportunities for students to develop professional networks and gain experience in cross-discipline collaborations through student exchanges and by serving on thesis committees at other PISCO campuses.

Such integration is highlighted by publications created by student and PI participation in cross-campus groups addressing issues of broad interest. For example, a group led by graduate students and research assistants from UCSC and OSU analyzed the influence of longterm research on advances in ecology and environmental policy (Hughes et al., 2017). Trainees undertook three analyses: (1) Using a literature search, they quantified citation frequencies of long-term (>4 years) versus short-term studies relative to journal impact factors. (2) They quantified the citation frequency of long-term studies in National Research Council (NRC) reports to policymakers. (3) They surveyed NRC report authors to quantify the authors' perspectives on the importance of long-term research in making policy recommendations. Relative to short-term research, the team found that long-term research was cited more frequently in journals, used more frequently in NRC reports, and considered more valuable by NRC authors in making policy recommendations (Hughes et al., 2017). Independent studies report similar conclusions (e.g., Kuebbing et al., 2018), suggesting that advances in conservation science theory and practice will depend heavily on long-term ecological and environmental research.

\section{REFLECTIONS ON 20 YEARS}

Large-scale and long-term research obviously requires collaboration. Over the program's 20 years, PISCO scientists have been highly collaborative, both within and outside the consortium. Collaboration-based advancements were made on all fronts: conservation, training, data management, and outreach. For example, PISCO time series have contributed baselines crucial in assessing impacts from oil spills, hypoxic events, species invasions, and disease epidemics, all of which recently have affected the CCLME (e.g., Grantham et al., 2004; Menge et al., 2016; Caselle et al., 2017; Miner et al., 2018). Collaborative groups can facilitate rapid, proactive responses to unexpected impacts in the forms of scientific research, sharing of information, and providing management advice (e.g., Adger et al., 2005). Coordinated networks also avoid costly startup delays and time-consuming relationship building (Ellis et al., 2011), which is critical in the face of rapid climate change (Duffy et al., 2013).

\section{Designing Decadal-Scale}

\section{Ecological Programs}

Long time series of marine ecological and oceanographic observations are fundamental for understanding ecosystem responses to climate change and other anthropogenic impacts. Integrating ecological and oceanographic time series is critically important for separating longterm natural trends from anthropogenicdriven variation. Parsing these sources of variation requires time series comparable 
in length to the natural climate regimes, some of which vary at decadal scales. For example, rocky intertidal communities have shifted northward over the past 20 to 30 years (Raimondi et al., 2019, in this issue) while fish communities are being "tropicalized" across a biogeographic transition zone (recent work of author Caselle and colleagues). Further, larval supply of both prey (mussels and barnacles) and predator (rockfishes) populations are sensitive to climate cycles ranging from shorter (e.g., El Niño, 3-7 years) to longer (North Pacific Gyre Oscillation and Pacific Decadal Oscillation, 10-30 years) (Caselle et al., 2010; Menge et al., 2019, in this issue). While observational approaches are key to long-term and large-scale pattern detection, determining causal linkages, especially in large data sets requires approaches such as running identical experiments at multiple sites along environmental gradients (i.e., the comparative-experimental approach; Menge and Menge, 2013). Large-scale replicated experimentation requires a consortium or network approach such as PISCO (for other examples, see the Kelp Ecosystem Ecology Network, http://www.kelpecosystems.org, and the Zostera Experimental Network, http://zenscience.org).

\section{Network Development and Coordination}

A long list of factors is necessary for success in creating a collaborative interdisciplinary network (e.g., Bruine de Bruin and Morgan, 2019; also see Brown et al., 2015). Examples include shared research goals, methodologies, effort, and benefits, and excellent students, adequate and longterm funding, and supportive institutions. We believe that PISCO hit the mark on all of these factors. In our view, however, perhaps the most critical requirement is strong, cohesive, mutually respectful, and supportive interpersonal interactions. From the start, PI membership was based on close interpersonal relationships as well as interest in common goals and demonstrable scientific excellence.
The ability of PIs to work positively and creatively together in a consensus-based decision-making environment made addressing organizational challenges possible. The result was a cohesive and coordinated network (Table 1) characterized by strong decisive communication and ability to follow through on agreements and resolve any differences that arose.

The second biggest challenge, after assembling a cohesive team, was obtaining ongoing funding. The PISCO consortium has been fortunate to have the DLPF as a strong and persistent partner in our enterprise; the foundation's enduring support jump-started the consortium and provided core funding to leverage support from agencies and other foundations.

Although PISCO progressed without a strongly hierarchical governance structure, coordination posed unique challenges, for example, in network size. How big is too big? How small is too small? Assuming, for example, that all PIs work in unison, decision-making and work planning can be easier in a relatively small group of close-knit, congenial colleagues. Thus, initially PISCO functioned well by choosing one PI to lead the relatively small group of eight PIs. This structure became less efficient as the number of PIs grew. The addition of carefully selected oceanographic, molecular physiology, and evolutionary genetic colleagues increased the PI team to 13 members. Our solution was to employ a program coordinator, create an executive committee with rotating membership, and ensure each campus was represented. This management structure provided stability and remains in effect. We believe this format would work in many multi-PI collaborations.

\section{Data Management}

The task of collecting, processing, analyzing, storing, and providing diverse streams of data across the PISCO network was an enormous challenge. Although oceanography has a long-standing tradition of archiving and sharing data, ecology has been slower in developing such systems. Initially, data sharing practices differed greatly between consortium oceanographers and ecologists. These divides have decreased, but some differences persist, likely due in part to the heterogeneous nature of biological data. Creating a universal data sharing policy in a group contributing data from different disciplinary "data cultures" was a major goal, and remains a work in progress.

PISCO has been an experiment of sorts for developing a coordinated data management program for ecological, oceanographic, and also physiological and genomic data. Initially, PISCO data were largely managed locally with an internal, web-based file sharing system for exchanging data across campuses. Better integration of these sometimes idiosyncratic data management programs began in earnest in 2005. With renewed funding and strong urging by our funders, PISCO data coordinators worked to develop metadata infrastructures to facilitate searching across data sets. Early decisions to use standards-based oceanographic and ecological metadata standards such as OPeNDAP and Ecological Metadata Language (EML) were at times difficult to operationalize. However, such approaches have been extraordinarily useful for setting field-specific metadata standards that allow us to make our data sets available and discoverable through a variety of platforms.

Following early collaborations with the Knowledge Network for Biodiversity (KNB), the Long Term Ecological Research Network (LTER), and the National Center for Ecological Analysis and Synthesis (NCEAS), we have made data available through other data systems such as BCO-DMO (https://www. bco-dmo.org) and DATAOne (https:// www.dataone.org). PISCO long-term ecosystem data are now currently available through these outlets and through project-specific visualization platforms, such as the one developed in partnership with the Multi-Agency Rocky Intertidal Network (MARINe; https://marine.ucsc. edu/explore-the-data/). For newly developing networks, we strongly suggest that 
data management programs be developed from the outset with adequate commitment of resources. Programs should include funding for personnel to support the often complex and highly dynamic tasks of environmental and ecological data management, archiving, and sharing.

\section{CONCLUDING REMARKS}

In the 1990s, despite working at the shoreward and seaward edges of the inner shelf, coastal oceanography and ecology were largely independent pursuits (Menge, 1992). Despite climate changeprompted calls for research addressing ecosystem structure and dynamics spanning small to large and short to long spatial and temporal scales (Levin, 1992), funding frustrated most ecologists with interest in pursuing these issues.

PISCO's journey from 1999 to 2019 has been exciting, full of new discoveries and productive advances in science application. Among our advances were: (1) creating a research and training platform that has successfully merged science with conservation, management, and policy at local, regional, national, and international levels; (2) providing theoretical and empirical information and new paradigms for the creation and monitoring of marine conservation approaches such as MPAs; (3) developing the longest quantitative, community-scale biogeographic data set on the globe, which has redefined biogeographic boundaries along the North American west coast, demonstrated climate-related northward shifts, and shown strong correspondence with ocean conditions; (4) discovering upwelling-driven hypoxia stress, ecological impacts of ocean acidification, and the coupled nature of ocean acidification and hypoxia; (5) showing that, at large scales, ecosystem dynamics are jointly driven by oceanic and ecological processes, and are sensitive to climate change; (6) providing insight into larval supply and connectivity among coastal ecosystems, how they scale to coastal populations, and their relationship to ocean conditions; (7) demonstrating the incomparable power of having flexibility in resources to meet challenges posed by ecological "surprises" such as hypoxia and sea star wasting; (8) showing the necessity of programs quantifying oceanic conditions in the inner shelf that are synchronized with ecological research; (9) helping to establish the value and insights achievable through interdisciplinary collaborative research that crosses molecular to large marine ecosystem levels of biological organization; and (10) training of a growing cohort of young marine scientists steeped in interdisciplinary and cross-disciplinary research and outreach with passionate interest in working to solve society's environmental problems. These and many other advances have dramatically increased scientific and societal understanding of the structure, dynamics, conservation, and management of coastal ecosystems. The strong momentum, new perspectives, and talent infusions emerging from our first 20 years make us optimistic that PISCO will continue gaining insights into inner shelf ecosystem dynamics, advancing conservation science, and helping society deal with the anthropogenic and climatedriven challenges ahead. @

\section{REFERENCES}

Adger, W.N., T.P. Hughes, C. Folke,

S.R. Carpenter, and J. Rockström. 2005. Socialecological resilience to coastal disasters. Science 309(5737):1,036-1,039, https://doi.org/ 10.1126/science.1112122.

Allison, G.W., S.D. Gaines, J. Lubchenco, and H.P. Possingham. 2003. Ensuring persistence of marine reserves: Catastrophes require adopting an insurance factor. Ecological Applications 13:8-24, https://doi.org/10.1890/1051-0761(2003)013 [0008:EPOMRC]2.0.CO;2.

Ammann, A.J. 2004. SMURFs: Standard Monitoring Units for the Recruitment of temperate reef Fishes. Journal of Experimental Marine Biology and Ecology 99:135-154, https://doi.org/10.1016/ j.jembe.2003.08.014.

Boonstra, W.J., and H. Osterblom. 2014. A chain of fools: Or, why is it so hard to stop overfishing? Maritime Studies 13:15, https://doi.org/10.1186/ s40152-014-0015-4.

Botsford, L.W., J.W. White, M.H. Carr, and J.E. Caselle. 2014. Marine protected area networks in California, USA. Advances in Marine Biology 69:205-251, https://doi.org/10.1016/ B978-0-12-800214-8.00006-2.

Brown, R.R., A. Deletic, and T.H.F. Wong. 2015. How to catalyse collaboration. Nature 525:315-317, https://doi.org/10.1038/525315a.

Bruine de Bruin, W., and M.G. Morgan. 2019. Reflections on an interdisciplinary collaboration to inform public understanding of climate change, mitigation, and impacts. Proceedings of the National
Academy of Sciences of the United States of America 116:7,676-7,683, https://doi.org/10.1073/ pnas.1803726115.

Caley, M.J., M.H. Carr, M.A. Hixon, T.P. Hughes, G.P. Jones, and B.A. Menge. 1996. Recruitment and the local dynamics of open marine populations. Annual Review of Ecology and Systematics 27:477-500, https://doi.org/10.1146/ annurev.ecolsys.27.1.477.

Carr, M.H., J.W. White, E. Saarman, J. Lubchenco, K. Milligan, and J.E. Caselle. 2019. Marine protected areas exemplify the evolution of science and policy. Oceanography 32(3):94-103, https://doi.org/ 10.5670/oceanog.2019.315.

Caselle, J.E., M.H. Carr, D.P. Malone, and D.E. Wendt. 2010. Can we predict interannual and regional variation in delivery of pelagic juveniles to nearshore populations of rockfishes (Genus Sebastes) using simple proxies of ocean conditions? Reports of California Cooperative Oceanic Fisheries Investigations 51:91-105.

Caselle, J.E., K. Davis, and L.M. Marks. 2017. Marine management affects the invasion success of a non-native species in a temperate reef system in California, USA. Ecology Letters 21:43-53, https://doi.org/10.1111/ele.12869.

Chan, F., J.A. Barth, C.A. Blanchette,

R.H. Byrne, F.P. Chavez, O.M. Cheriton, R.A. Feely, G.E. Friederich, B. Gaylord, T.C. Gouhier, and others. 2017. Persistent spatial structuring of coastal ocean acidification in the California Current System. Scientific Reports 7:2526, https://doi.org/ 10.1038/s41598-017-02777-y.

Chan, F., J.A. Barth, K.J. Kroeker, J. Lubchenco, and B.A. Menge. 2019. The dynamics and impact of ocean acidification and hypoxia: Insights from sustained investigations in the Northern California Current Large Marine Ecosystem. Oceanography 32(3):62-71, https://doi.org/ 10.5670/oceanog. 2019.312.

Cochrane, K.L., C.J. Augustyn, T. Fairweather, D. Japp, K. Kilongo, J. litembu, N.M. Moroff, J.P. Roux, L. Shannon, B. Van Zul, and others. 2009. Coastal Management 37:235-254, https://doi.org/ 10.1080/08920750902851187.

Diaz, R.J., and R. Rosenberg. 1995. Marine benthic hypoxia: A review of its ecological effects and the behavioural responses of benthic macrofauna. Oceanography and Marine Biology Annual Review 33:245-303.

Duffy, J.E., L.A. Amaral-Zettler, D.G. Fautin, G. Paulay, T.A. Rynearson, H.M. Sosik, and J.J. Stachowicz. 2013. Envisioning a marine biodiversity observation network. BioScience 63:350-361, https://doi.org/ 10.1525/bio.2013.63.5.8.

Ellis, S.L., L.S. Incze, P. Lawton, H. Ojaveer, B.R. MacKenzie, C.R. Pitcher. T.C. Shirley, M. Eero, J.W. Tunnell Jr., P.J. Doherty, and B.M. Zeller. 2011. Four regional marine biodiversity studies: Approaches and contributions to ecosys tem based management. PLOS ONE 6(4):e18997, https://doi.org/10.1371/journal.pone.0018997.

Feely, R.A., C.L. Sabine, J.M. Hernandez-Ayon, D. lanson, and B. Hales. 2008. Evidence for upwelling of corrosive "acidified" water onto the continental shelf. Science 320:1,490-1,492, https://doi.org/ 10.1126/science.1155676.

Feely, R.A., C.L. Sabine, K. Lee, W. Berelson, J. Kleypas, V.J. Fabry, and F.J. Millero. 2004. Impact of anthropogenic $\mathrm{CO}_{2}$ on the $\mathrm{CaCO}_{3}$ system in the oceans. Science 305:362-366, https://doi.org/ 10.1126/science.1097329.

Fischhoff, B., and D.A. Scheufele. 2013. The science of science communication. Proceedings of the National Academy of Sciences of the United States of America 110(Supplement 3):14,031-14,032, https://doi.org/10.1073/pnas.1312080110.

Grantham, B.A., F. Chan, K.J. Nielsen, D.S. Fox, J.A. Barth, A. Huyer, J. Lubchenco, and B.A. Menge. 2004. Upwelling-driven nearshore hypoxia signals ecosystem and oceanographic changes in the Northeast Pacific. Nature 429:749-754, https://doi.org/10.1038/nature02605. 
Hofmann, G.E., J. Barry, P. Edmunds, R.D. Gates, D.A. Hutchins, T. Klinger, and M.A. Sewell. 2010. The effect of ocean acidification on calcifying organisms in marine ecosystems: An organism-to-ecosystem perspective. Annual Review of Ecology, Evolution and Systematics 41:127-147, https://doi.org/10.1146/ annurev.ecolsys.110308.120227.

Hughes, B.B., R. Beas-Luna, A.K. Barner, K. Brewitt, D.R. Brumbaugh, E.B. Cerny-Chipman, S.L. Close, K.E. Coblentz, K.L. de Nesnera, S.T. Drobnitch, and others. 2017. Long-term studies contribute disproportionately to ecology and policy. BioScience 67:271-281, https://doi.org/10.1093/ biosci/biw185.

IPCC (Intergovernmental Panel on Climate Change). 2001. Climate Change 2001: Synthesis Report A Contribution of Working Groups I, II, and III to the Third Assessment Report of the Intergovernmental Panel on Climate Change. R.T. Watson and the Core Writing Team, eds, Cambridge University Press, Cambridge, UK, and New York, NY, USA, 398 pp., https://www.ipcc.ch/report/ar3/syr/.

Kahan, D., D. Scheufele, and K.H. Jamieson. 2017. Introduction: Why science communication? In The Oxford Handbook of the Science of Science Communication, K. Jamieson, D. Scheufele, and D. Kahan, eds, Oxford University Press, Oxford, UK, https://doi.org/10.1093/ oxfordhb/9780190497620.013.1.

Kleypas, J. 1999. Geochemical consequences of increased atmospheric carbon dioxide on coral reefs. Science 284:118-120, https://doi.org/10.1126/ science.284.5411.118.

Kuebbing, S.E., A.P. Reimer, S.A. Rosenthal, G. Feinberg, A. Leiserowitz, J.A. Lau, and M.A. Bradford. 2018. Long-term research in ecology and evolution: A survey of challenges and opportunities. Ecological Monographs 88:245-258, https://doi.org/10.1002/ecm.1289.

Lester, S.E., B.S. Halpern, K. Grorud-Colvert, J. Lubchenco, B.I. Ruttenberg, S.D. Gaines, S. Airame, and R.R. Warner. 2009. Biological effects within no-take marine reserves: A global synthesis. Marine Ecology Progress Series 384:33-46, https://doi.org/10.3354/meps08029.

Levin, S.A. 1992. The problem of pattern and scale in ecology. Ecology 73:1,943-1,967, https://doi.org/ $10.2307 / 1941447$.

Lubchenco, J., S.R. Palumbi, S.D. Gaines, and S. Andelman. 2003. Plugging a hole in the ocean: The emerging science of marine reserves. Ecological Applications 13(sp1):3-7, https://doi.org/10.1890/1051-0761(2003)013 [0003:PAHITO]2.0.CO;2.

Lubchenco, J., B.A. Menge, J.A. Barth, M.H. Carr J.E. Caselle, F. Chan, H.K. Fulton-Bennett, S.D. Gaines, K.J. Kroeker, K. Milligan, and others 2019. Connecting science to policymakers, managers, and citizens. Oceanography 32(3):106-115, https://doi.org/10.5670/oceanog.2019.317.

Menge, B.A. 1992. Community regulation: Under what conditions are bottom-up factors important on rocky shores? Ecology 73:755-765, https://doi.org/ 10.2307/1940155.

Menge, B.A., E.B. Cerny-Chipman, A. Johnson, J.M. Sullivan, S.A. Gravem, and F. Chan. 2016. Sea star wasting disease in the keystone predator Pisaster ochraceus in Oregon: Insights into differential population impacts, recovery, predation rate, and temperature effects from long-term research. PLOS ONE 11:e0153994, https://doi.org/10.1371/ ournal.pone.0153994.

Menge, B.A., and D.N.L. Menge. 2013. Dynamics of coastal meta-ecosystems: The intermittent upwelling hypothesis and a test in rocky intertidal regions. Ecological Monographs 83:283-310, https://doi.org/10.1890/12-1706.1.

Menge, B.A., J.E. Caselle, J.A. Barth, C.A. Blanchette, M.H. Carr, F. Chan, S. Gravem, T.C. Gouhier, J. Lubchenco, M.A. McManus, and others. 2019. Community responses to climate-related vari- ability and disease: The critical importance of long-term research. Oceanography 32(3):72-81, https://doi.org/10.5670/oceanog.2019.313.

Miner, C.M., J.L. Burnaford, R.F. Ambrose, L. Antrim, H. Bohlmann, C.A. Blanchette, J.M. Engle, S.C. Fradkin, R. Gaddam, C.D.G. Harley, and others 2018. Large-scale impacts of sea star wasting disease (SSWD) on intertidal sea stars and implications for recovery. PLOS ONE 13:e0192870, https://doi.org/10.1371/journal.pone.0192870.

Pauly, D. 1995. Anecdotes and the shifting baseline syndrome of fisheries. Trends in Ecology and Evolution 10:430, https://doi.org/10.1016/ S0169-5347(00)89171-5.

Raimondi, P.T. C. Melissa Miner, B.A. Menge, C.A. Blanchette, and D.P. Lohse. 2019 Quantitative biogeography: Large-scale, longterm change in the rocky intertidal region of the California Current Large Marine Ecosystem. Oceanography 32(3):26-37, https://doi.org/ $0.5670 /$ oceanog. 2019.308.

Ramesh, R., Z. Chen, V. Cummins, J. Day, C. D'Elia, B. Dennison, D.L. Forbes, B. Glaeser, M. Glaser, B. Glavovic, and others. 2015. Land-ocean interactions in the coastal zone: Past, present, \& future. Anthropocene 12:85-98, https://doi.org/10.1016/ j.ancene.2016.01.005.

Reid, W.V. 2004. Bridging the science-policy divide. PLOS Biology 2(2):e27, https://doi.org/10.1371/ journal.pbio.0020027.

Vitousek, P.M., H.A. Mooney, J. Lubchenco, and J.M. Melillo. 1997. Human domination of Earth's ecosystems. Science 277:494-499, https://doi.org/ 10.1126/science.277.5325.494.

\section{ACKNOWLEDGMENTS}

We are indebted to the vision and sustained support from the David and Lucile Packard Foundation (DLPF). Foundation officers Walt Reid, Barry Gold, Kai Lee, Heather Ludemann, and Chad English pro vided key advice about program design and strategic planning. The authors thank anonymous reviewers for comments. Satie Airame, Renee Davis, Liz Riley, Emily Saarman, and Cindy Kent provided program, outreach, and engagement support. DLPF award \#2017-65575 helped support the develop ment of this manuscript. The Gordon and Betty Moore Foundation's co-support in 2004-2009 was essential to our growth and ability to be a long-term program. State, federal, and other philanthropic awards have also supported work through funding and partnerships, including those from NSF, NOAA National Marine Sanctuaries, Oregon and California Departments of Fish and Wildlife, US Bureau of Ocean Energy Management, state parks, and US national parks. This is PISCO contribution 490.

\section{AUTHORS}

All authors developed the PISCO program.

- The article lead authors are Bruce A. Menge (mengeb@oregonstate.edu), Department of Integrative Biology, Oregon State University, Corvallis, OR, USA; Kristen Milligan, Oregon State University, Corvallis, OR, USA; Jennifer E. Caselle, Marine Science Institute, University of California, Santa Barbara, Santa Barbara, CA, USA.

- Contributors from Oregon State University are John A. Barth, College of Earth, Ocean, and Atmospheric Sciences; Jane Lubchenco, Francis Chan, and Mark Novak, Department of Integrative Biology; Robert K. Cowen, Director, Hatfield Marine Science Center; and J. Wilson White, Coastal Oregon Marine Experiment Station and Fisheries and Wildlife.

- Contributors from the Marine Science Institute at the University of California, Santa Barbara, are Carol A. Blanchette, Steven D. Gaines, Gretchen E. Hofmann, Robert R. Warner, and Libe Washburn.

- Principal Investigators from the Department of Ecology and Evolutionary Biology, University of California, Santa Cruz, are Mark H. Carr, Kristy J. Kroeker, and Peter T. Raimondi.

- Contributors from of Stanford University are Mark Denny and George N. Somero, Hopkins Marine Station; and Stephen R. Palumbi, Department of Biology.

- The contributor from the Department of Oceanography, University of Hawai'i at Mānoa, is Margaret A. McManus (previously University of California, Santa Cruz).

\section{ARTICLE CITATION}

Menge, B.A., K. Milligan, J.E. Caselle, J.A. Barth, C.A. Blanchette, M.H. Carr, F. Chan, R.K. Cowen, M. Denny, S.D. Gaines, G.E. Hofmann, K.J. Kroeker, J. Lubchenco, M.A. McManus, M. Novak, S.R. Palumbi, P.T. Raimondi, G.N. Somero, R.R. Warner, L. Washburn, and J.W. White. 2019. PISCO: Advances made through the formation of a large-scale, long-term consortium for integrated understanding of coastal ecosystem dynamics. Oceanography 32(3):16-25, https://doi.org/ 10.5670/oceanog.2019.307.

\section{COPYRIGHT \& USAGE}

This is an open access article made available under the terms of the Creative Commons Attribution 4.0 International License (https://creativecommons.org/ licenses/by/4.0/), which permits use, sharing, adaptation, distribution, and reproduction in any medium or format as long as users cite the materials appropriately, provide a link to the Creative Commons license, and indicate the changes that were made to the original content.

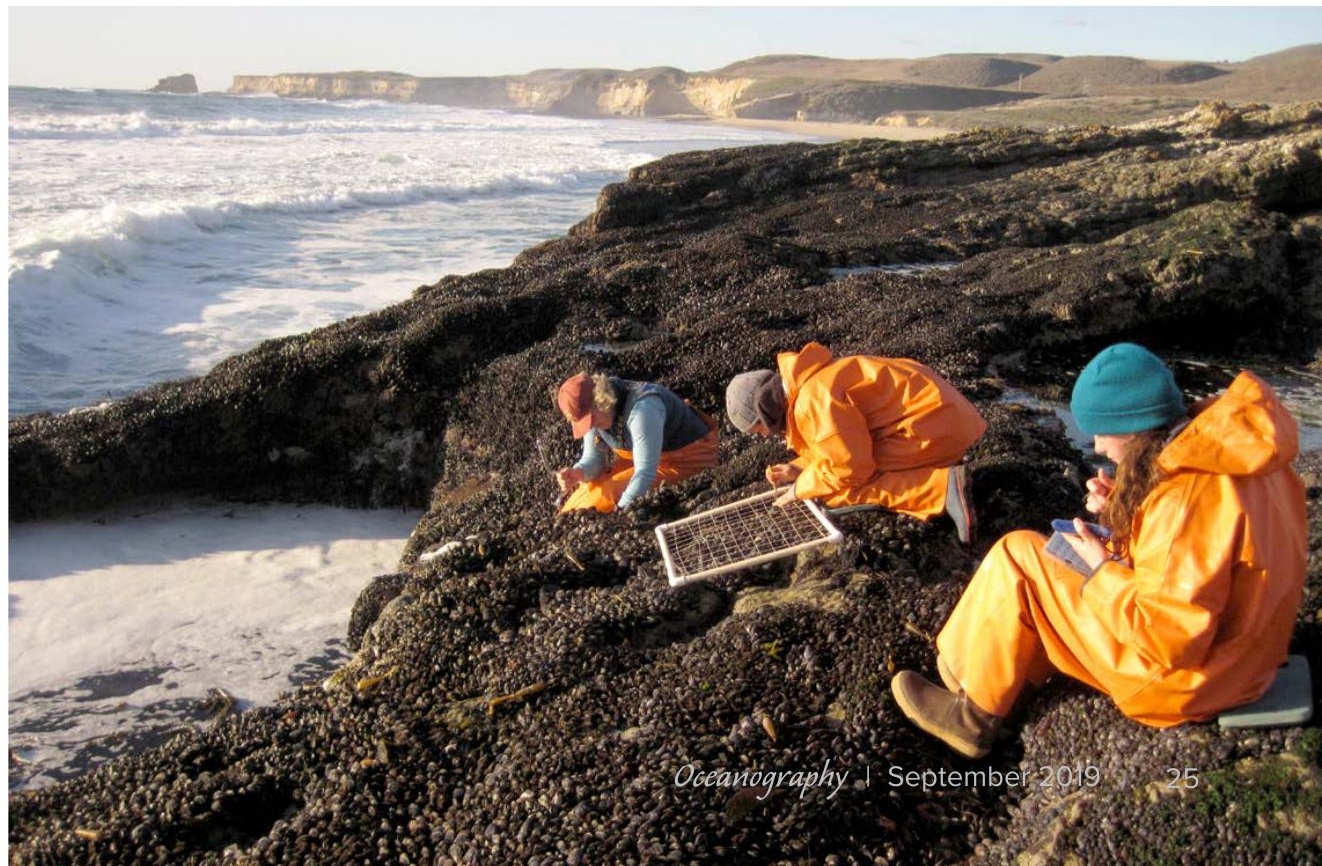

